\title{
Efficacy of Extracorporeal Irradiation in Primary Malignant Bone Tumours: A Tertiary Cancer Centre Experience
}

\author{
Gunaseelan K $\mathbf{K}^{1}$, Dilip Kumar Patro ${ }^{2}$, Arun Lal ${ }^{3}$, Kannan $\mathbf{P}^{4}$, Biswajit $\mathbf{D}^{5}$, \\ Vijayaprabhu $\mathrm{N}^{6}$
}

${ }^{1}$ Additional Professor, Regional Cancer Centre, JIPMER, India. ${ }^{2}$ Professor Department of Orthopaedics JIPMER, India. ${ }^{3}$ Senior Resident, Department of Orthopaedics, JIPMER, India. ${ }^{4}$ Senior Resident, Department of Radiation Oncology, JIPMER, India. ${ }^{5}$ Additional Professor, Department of Medical Oncology, JIPMER, India. ${ }^{6}$ Assistant Professor, Medical Physics, Department of Radiotherapy, JIPMER, India.

\begin{abstract}
Background: Limb-sparing approaches involving a combination of surgery, chemotherapy, and radiotherapy are preferred in primary malignant bone tumours whenever possible. The limb function can be maintained by performing reconstruction either using a prosthesis or bone graft. Extracorporeal irradiation is a novel and exciting technique in which the restoration is done using the patient's own tumour bone. In this article, we present the local control, complications, and functional outcome of 49 cases of primary malignant bone tumours treated using the technique of extracorporeal irradiation. Materials and methods: 49 patients with primary malignant bone tumours were treated with extracorporeal irradiation between the year 2007 to 2015.En-bloc resection of the tumour and the involved bone along with soft tissues was performed about four weeks after the completion of three to four cycles of neoadjuvant chemotherapy. The bone segment was irradiated with 6MV linear accelerator to a dose of 50Gy. After extracorporeal irradiation, the bone was re-implanted using fixation devices. Local control, relapse-free survival, complications and functional outcome were studied. Results: Out of 49 patients, there were 33 males and 16 females. The median age was 19 years. Femur and tibia were the most common tumour locations with osteosarcoma being the most common histology (74\%). The local control rate was $94 \%$. The 8 year local recurrence-free survival and distant metastasis-free survival were $89 \%$ and $84 \%$ respectively. The overall complication rate was $20 \%$. Infection was the most frequent complication, observed in $46 \%$ of the patients who developed complications. Out of 49 patients, 40 had reported a good range of movements. Conclusion: Extracorporeal irradiation and re-implantation is a convenient alternative to prosthesis from a health economics point of view, provided severe complications are managed and avoided so that functional results can be achieved.
\end{abstract}

Keywords: Malignant bone tumours- extracorporeal irradiation- prosthesis- sarcomas

Asian Pac J Cancer Care, 4 (2), 53-57

\section{Introduction}

Primary malignant bone tumours are common in children and adolescents because of active skeletal growth. About sixty percentage cases occur between 10 and 20 years of age [1]. The standard management approach for malignant bone tumours is multidisciplinary, especially when there is a concern for limb salvage. The treatment of malignant bone tumours has undergone a drastic change in the last 20 years. Limb-sparing strategies are preferred whenever possible, which may involve a combination of
Submission Date: 12/15/2018 Acceptance Date: 02/09/2019

Corresponding Author:

Dr. Gunaseelan K

Additional Professor, Regional Cancer Centre, JIPMER, India.

Email: gunapgi@gmail.com 
the limb function The various methods of sterilisation include autoclaving, pasteurisation, use of liquid nitrogen and extracorporeal irradiation (ECI). Extracorporeal irradiation is a novel and exciting technique. In ECI, the tumour bearing segment of bone is excised en bloc; the tumour and the soft tissues are then removed from the bone, and the bone is irradiated and reimplanted back into the body [7-11]. In this article, we analyse and present the results of malignant bone tumours treated using the technique of extracorporeal irradiation.

\section{Materials and Methods}

Forty-nine histologically proved non-metastatic primary malignant bone tumours suitable for limb preservation therapy, from the year 2007 to 2015, were included in this study after tumour board discussion. The eligible patients underwent a clinical examination by a multidisciplinary team and magnetic resonance imaging of the affected limb to assess the local extent of the disease. Contrast-enhanced CT of the thorax and bone scan were done to exclude lung and bone metastases respectively. Other routine investigations included complete haemogram, renal function test, and liver function test. The patients were usually treated with neoadjuvant chemotherapy followed by surgery, ECI and reimplantation followed by adjuvant chemotherapy. Patients with osteosarcoma were given IAP [Ifosfamide $1.5 \mathrm{~g} / \mathrm{m}^{2}$ day $1,2 \& 3$, Adriamycin $60 \mathrm{mg} / \mathrm{m}^{2}$ day 1 , and cisplatin $100 \mathrm{mg} / \mathrm{m} 2$ divided over days $1-3$ ) regimen every three weeks for six cycles. Ewings sarcoma patients were treated with alternating VAC (vincristine $1.5 \mathrm{mg} / \mathrm{m}^{2}$ day 1, Adriamycin $60 \mathrm{mg} / \mathrm{m} 2$ day 1 , and cyclophosphamide $1200 \mathrm{mg} / \mathrm{m}^{2}$ day 1 ) and IE (ifosfamide $1.8 \mathrm{~g} / \mathrm{m}^{2} /$ day for 5 days, etoposide $100 \mathrm{mg} / \mathrm{m}^{2} /$ day for 5 days) regimen every three weeks for a total of 16 cycles.

Neoadjuvant chemotherapy was given for three to four cycles. Surgery was performed about four weeks after the completion of neoadjuvant chemotherapy. The surgical procedure and ECI technique is summarised inb figure During operation, the tumour bearing segment of the bone is removed en bloc along with soft tissues. The tumour and the soft tissues are then removed from the bone, which is wrapped in a sterile towel and further twice wrapped in sterile plastic bags and sent for radiation in an acrylic phantom. Sterile saline water(tissue equivalent) was poured in the phantom. The bone segment was irradiated in the radiotherapy department with $6 \mathrm{MV}$ linear accelerator to a dose of $50 \mathrm{~Gy}$ using parallel opposed lateral beams.
During the ECI, the operative site was prepared for reimplantation, and biopsy was performed at all osteotomy sites to assess the status of resection margins. After ECI, the bone was then reimplanted using fixation devices under C-arm guidance. During the postoperative period, immobilization was continued until the radiographic imaging showed evidence of union. Full weight bearing was allowed according to the clinical and radiological progress.

The local control, relapse-free survival, complications and functional outcome were studied. The functional outcome was reported as good, fair, and poor based on the criteria used by Uyttendaele et al [12], as shown in Table 1.

\section{Results}

49 patients with primary malignant bone tumours were treated with extracorporeal irradiation technique at our institute between 2007 and 2015. The clinical and tumour characteristics were shown in Table 1 . The predominant histology was osteosarcoma (74\%). Other histologies included ewings sarcoma and chondrosarcoma. Majority of patients were males $(67 \%)$. The age group of the patients ranged from nine to 40 years and the median age was 19 years. The long bones of the lower limbs were most frequently affected and nearly $90 \%$ of the tumors were located in femur and tibia. The median duration of follow up was 24 months (range 4-108 months).

Ten patients had developed recurrence either in the form of only local (two patients), distant metastases (seven patients) or both (one patient). The local control rate was $94 \%$. The 8 year local recurrence free survival was $84 \%$. The 8 year distant metastasis free survival was $84 \%$. The type of complication that had occurred in the perioperative period is shown in figure. The overall complication rate was $20 \%$. The most frequent

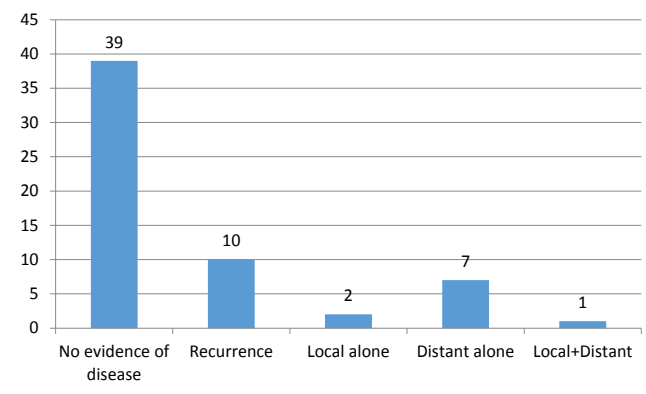

Figure 1. Disease Status

Table 1. Assessment of Orthopaedic Outcome

\begin{tabular}{ll}
\hline & \multicolumn{1}{c}{ Criteria used to classify the functional results } \\
\hline \multirow{2}{*}{ useful position and range of movement at any joint involved } \\
no problems with activities of daily living \\
acceptable cosmetic appearance \\
no need for external support during walking \\
Fair & fails to meet the above-mentioned criteria but the patient is pleased \\
Poor & patient would have been better off with an external prosthesis after a radical resection \\
\hline
\end{tabular}


Table 2. Patient and Tumour Characteristics

\begin{tabular}{lcc}
\hline Characteristic & Number & Percentage \\
\hline Male & Gender & 67 \\
Female & 33 & 33 \\
& 16 & \\
Median & Age & \\
Range & 19 years & \\
& $9-40$ years & 49 \\
Femur & Tumour location & 41 \\
Tibia & 24 & 4 \\
Humerus & 20 & 4 \\
Radius & 2 & 2 \\
Fibula & 2 & \\
& 1 & 74 \\
Osteosarcoma & Histology & 8 \\
Ewings sarcoma & 46 & 6 \\
Chondrosarcoma & 3 & 12 \\
Others & 6 & \\
Median & Follow up & \\
Range & 24 months & \\
\hline
\end{tabular}

complication was infection, seen in $46 \%$ of the patients who developed complications. With respect to orthopedic outcome, 40 patients had reported good range of movements as shown in figure 4 . At the end of last follow up, out of 49 treated patients, 37 patients were alive, 9 patients had expired and 3 were lost to follow up.

\section{Discussion}

Limb sparing procedures are the preferred options for malignant bone tumours whenever feasible [4]. Custom made prostheses or osteoarticular allografts can be used for reconstruction but prostheses are expensive and cannot be afforded by all patients in developing countries. Moreover, high complication rates, with $30 \%$ infection and $23 \%$ nonunion, have been reported using allografts, especially in children. Patients with graft complications had a significantly lower probability of graft survival, resulting in a worse functional outcome [7-8-13]. These problems can be overcome by the technique of using the

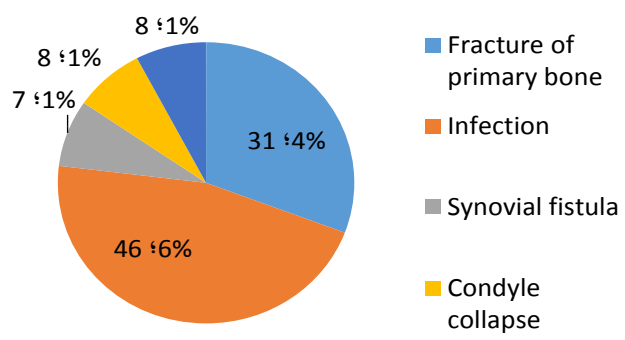

Figure 2. Complications

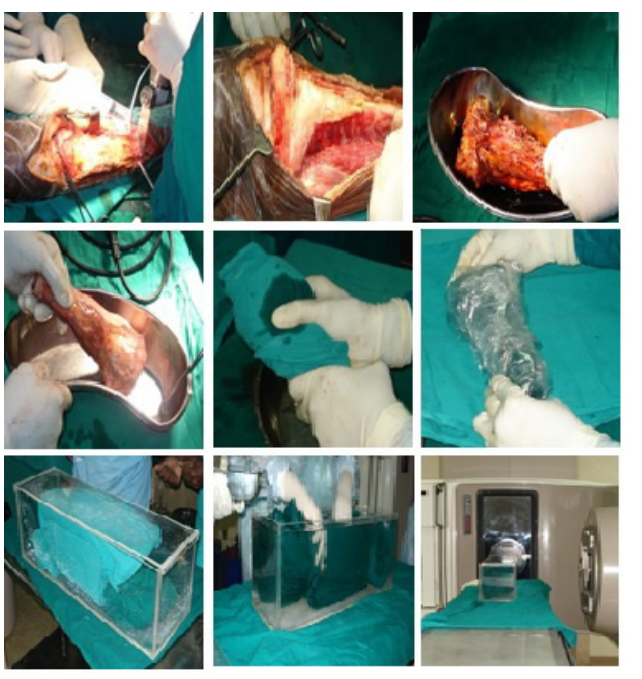

Figure 3. Extracorporeal Irradiation Technique

patients own bone as autograft for reconstruction after extracorporeal irradiation. This technique of extracorporeal irradiation and reimplantation was first developed by Spira and Lubin [14]. There are only limited reports of ECI available in the literature [9-14-16]. ECI has several advantages over other methods of limb reconstruction. These include precise anatomic fit, preservation of joint mobility, avoidance of limb length discrepancy and problems associated with allograft, such as dependence on a bone bank, graft rejection, and the risk of viral transmission such as the human immunodeficiency and hepatitis $\mathrm{C}$ viruses.

Extracorporeal irradiation as an useful, costeffective alternative during limb salvage in bony malignancies had been reported by various studies. The studies by Davidson et al. [15], and Poffyn et al. [16] were the largest in the literature of ECI that had treated 50 or more patients. Ours is the next largest study that had included 49 patients of primary malignant bone tumours managed with ECI. Davidson et al. [15] in study treated 50 patients with

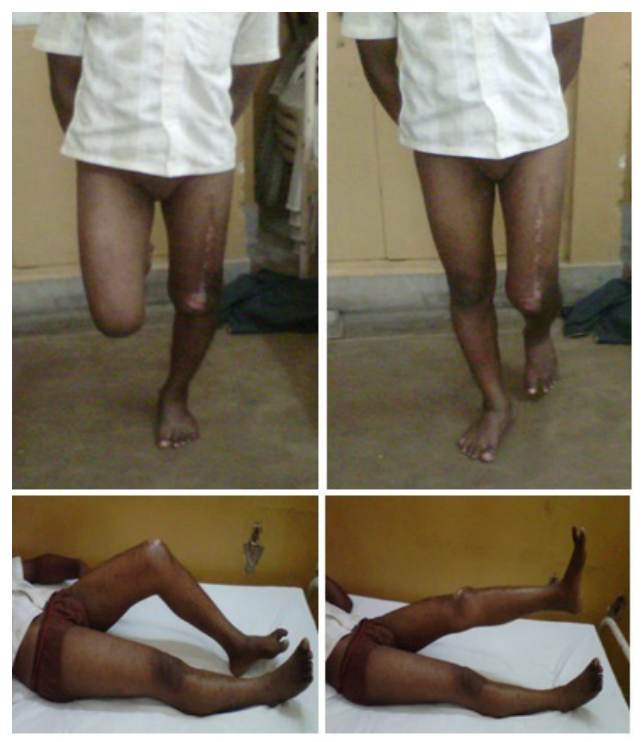

Figure 4. Orthopaedic Outcome 
Table 3. Literature Review of Local Complications

\begin{tabular}{|c|c|c|c|c|c|}
\hline & $\begin{array}{l}\text { Hong et al.(9) } \\
\qquad \mathrm{N}=16\end{array}$ & $\begin{array}{l}\text { Sys et al.(21) } \\
\qquad \mathrm{N}=15\end{array}$ & $\begin{array}{l}\text { Uyttendale et al.(12) } \\
\qquad \mathrm{N}=15\end{array}$ & $\begin{array}{l}\text { Davidson et al.(15) } \\
\qquad \mathrm{N}=50\end{array}$ & $\begin{array}{c}\text { JIPMER } \\
\mathrm{N}=49\end{array}$ \\
\hline Infection & 1 & 3 & 2 & 3 & 6 \\
\hline Nonunion & 0 & 1 & 1 & 9 & 1 \\
\hline Fracture & 1 & 0 & 1 & 3 & 4 \\
\hline Amputation & 1 & 0 & 3 & 0 & 0 \\
\hline Reoperation & 0 & 1 & 5 & 17 & 1 \\
\hline
\end{tabular}

extracorporeal irradiation and reimplantation and found four recurrences at a mean follow up of 38 months. Poffyn et al. [16] retrospectively reviewed 107 patients with 108 malignant or locally aggressive bone tumours treated between 1978 and 2009 by extracorporeal irradiation with 300 Gy to eradiacte the tumour, and reimplantation of the bone as an orthotopic autograft. No local recurrences were detected in the irradiated grafts. In the study of 12 patients with Ewings sarcoma by Puri et al. [17], six patients were free of disease and six patients had died from the disease at the time of last review and there were two recurrences around the operative site but away from the irradiated graft. Sharma et al. [18] treated 12 patients of primary malignant bone tumours with 50 Gy ECI dose and found 3 local recurrences at a median follow up of 22 months. The 2 year local recurrence free survival was $73 \%$. In our study, ten patients had developed recurrence either in the form of only local (two patients), distant metastases ( seven patients) or both (one patient) at a median follow up of 24 months. The local control rate was $94 \%$. The 8 year local recurrence free survival was $89 \%$. At the end of last review, out of 49 treated patients, 37 patients were alive, 9 patients had expired and 3 were lost to follow up. Thus, the local control rate and recurrences were varying among the studies, which could be attributed to the small sample size and varying doses of radiation used for ECI.

The optimal dose of ECI has not been determined. The radiation doses varying fom 50 to $300 \mathrm{~Gy}$ had been used in the literature. Chen et al. [19], Uyttendaele et al. [12], and Poffyn et al. [16] used doses of 300 Gy. In our study, we delivered midplane dose of 50Gy in one fraction using Source to axis distance(SAD) technique with parallel opposed lateral beams. Hong et al. [9] and Davidson et al. [15] delivered doses of 50 Gy similar to our study. The risk of wound infection and other complication in various ECI series had been reported to be upto $8-17 \%$ [17-20]. Sharma et al. [18] found wound infection rate of $14 \%$ ( 2 out of 14 patients). In our study, the infection rate was $12 \%$ which is similar to that reported in the literature. The lierature review of various local complications is shown in Table 3.

The limitation of this study is that it is not a randomized study to establish extracorporeal irradiation and reimplantation as the standard technique in bone tumours when limb salvage is concerened. Even in the literature, only retrospective and non randomised studies are available. Hence, in the future, it would be worth doing a randomised study comparing extracorporeal irradiation to prostheses.

In conclusion, Limb salvage approach involving multidisciplinary team is the current recommended treatment of choice for primary malignant bone tumours whenever feasible. Extracorporeal irradiation is a convenient alternative to prosthesis since affordability is a matter of concern in developing countries. If serious complications can be managed or avoided, functional results can be achieved. Thus, from a health economics point of view, ECI is a relatively low-cost technique compared with the high cost of prostheses. However, the most important determinants of the feasibility of ECI include tumour location and extent, and appropriate selection of patients.

\section{References}

1. Eyre R, Feltbower RG, Mubwandarikwa E, Eden TO, McNally RJ. Epidemiology of bone tumours in children and young adults. Pediatr Blood Cancer 2009 Dec;53(6):941-52.

2. Bernstein M, Kovar H, Paulussen M, Randall RL, Schuck A, Teot LA, et al. Ewing's sarcoma family of tumors: current management. Oncologist 2006 May;11(5):503-19.

3. Donaldson SS, Torrey M, Link MP, Glicksman A, Gilula L, Laurie F, et al. A multidisciplinary study investigating radiotherapy in Ewing's sarcoma: end results of POG \#8346. Pediatric Oncology Group. Int J Radiat Oncol Biol Phys 1998 Aug 1;42(1):125-35.

4. Gebhardt MC, Eyre R, Feltbower RG, Mubwandarikwa E, Eden TO, McNally RJ. What's new in musculoskeletal oncology. Int J Radiat Oncol Biol Phys 2002 Apr;84-A(4):694-701.

5. Hogendoorn PC, Athanasou N, Bielack S, De AE, Dei Tos AP, Ferrari S, et al. Bone sarcomas: ESMO Clinical Practice Guidelines for diagnosis, treatment and follow-up. Ann Oncol 2010 May;21 Suppl 5:v204-v213.

6. Jaffe N, Patel SR, Benjamin RS. Chemotherapy in osteosarcoma. Basis for application and antagonism to implementation; early controversies surrounding its implementation. Ann Oncol 1995 Aug;9(4):825-40.

7. Cannon SR. Massive prostheses for malignant bone tumours of the limbs. J Bone Joint Surg Br 1997 May;79(3):497-506.

8. Hejna MJ, Gitelis S. Allograft prosthetic composite replacement for bone tumors. Semin Surg Oncol 1997 Jan;13(1):18-24.

9. Hong A, Stevens G, Stalley P, Pendlebury S, Ahern V, Ralston A, et al. Extracorporeal irradiation for malignant bone tumors. Int J Radiat Oncol Biol Phys 2001 Jun $1 ; 50(2): 441-7$.

10. Khattak MJ, Umer M, Haroon uR, Umar M. Autoclaved tumor bone for reconstruction: an alternative in developing countries. Clin Orthop Relat Res 2006 Jun;447:138-44.

11. Singh VA, Nagalingam J, Saad M, Pailoor J. Which is the best method of sterilization of tumour bone for reimplantation? 
A biomechanical and histopathological study. Biomed Eng Online 2010 Sep 10;9:48.

12. Uyttendaele D, De SA, Claessens H, Roels H, Berkvens P, Mondelaers W. Limb conservation in primary bone tumours by resection, extracorporeal irradiation and re-implantation. J Bone Joint Surg Br 1988 May;70(3):348-53.

13. Mankin HJ, Gebhardt MC, Jennings LC, Springfield DS, Tomford WW. Long-term results of allograft replacement in the management of bone tumors. Clin Orthop Relat Res 1996 Mar;(324):86-97.

14. Spira E, Lubin E. Extracorporeal irradiation of bone tumors. A preliminary report. Isr J Med Sci 1968 Sep;4(5):1015-9.

15. Davidson AW, Hong A, McCarthy SW, Stalley PD. En-bloc resection, extracorporeal irradiation, and re-implantation in limb salvage for bony malignancies. J Bone Joint Surg Br 2005 Jun;87(6):851-7.

16. Poffyn B, Sys G, Mulliez A, Van MG, Van HL, Forsyth $\mathrm{R}$, et al. Extracorporeally irradiated autografts for the treatment of bone tumours: tips and tricks. Int Orthop 2011 Jun;35(6):889-95.

17. Puri A, Gulia A, Agarwal M, Jambhekar N, Laskar S. Extracorporeal irradiated tumor bone: A reconstruction option in diaphyseal Ewing's sarcomas. Indian J Orthop 2010 Oct;44(4):390-6.

18. Sharma DN, Rastogi S, Bakhshi S, Rath GK, Julka PK, Laviraj MA, et al. Role of extracorporeal irradiation in malignant bone tumors. Indian J Cancer 2013 Oct;50(4):3069.

19. Chen WM, Chen TH, Huang CK, Chiang CC, Lo WH. Treatment of malignant bone tumours by extracorporeally irradiated autograft-prosthetic composite arthroplasty. J Bone Joint Surg Br 2002 Nov;84(8):1156-61.

20. Araki N, Myoui A, Kuratsu S, Hashimoto N, Inoue T, Kudawara I, et al. Intraoperative extracorporeal autogenous irradiated bone grafts in tumor surgery. Clin Orthop Relat Res 1999 Nov;(368):196-206.

\section{(i) (5)}

This work is licensed under a Creative Commons AttributionNon Commercial 4.0 International License. 